\title{
Hanseníase ocular: uma abordagem histórica
}

\author{
Ocular leprosy: a historical approach
}

Jacob Moysés Cohen

Trabalho realizado no Instituto de Oftalmologia de Manaus (AM) - Brasil.

Professor Associado do Departamento de Clínica Cirúrgica da Faculdade de Medicina da Universidade Federal do Amazonas - Manaus (AM) - Brasil.

Endereço para correspondência: Jacob Moysés Cohen. Av. Sete de Setembro, 1.613 - Manaus (AM) CEP 69005-141

E-mail: jacobcohen@vivax.com.br

Recebido para publicação em 14.02.2008

Última versão recebida em 06.02.2009

Aprovação em 20.05.2009

\begin{tabular}{|l|}
\hline RESUMO \\
\hline Houve uma acentuada queda na prevalência da hanseníase nas últimas \\
três décadas. Contudo, a incidência não diminuiu na mesma proporção. \\
Hoje, três anos após a última data estipulada pela Organização Mundial da \\
Saúde para o controle da hanseníase, pacientes considerados curados \\
ainda necessitam de cuidados especiais por causa de suas incapacidades \\
e reações imunológicas. A literatura médica refere cegueira em 4\% a 11\% \\
dos pacientes estudados e, mais de 20\% com graves problemas visuais \\
devido a exposição da córnea, invasão bacilar e hipersensibilidade; estes \\
mecanismos resultam emuma população de aproximadamente 1 milhão de \\
pacientes cegos, embora a prevalência oficial não passe de 250.000 \\
pacientes em todo o mundo. O autor destaca a necessidade de melhor \\
tratamento e acompanhamento dos pacientes e, conclama os oftalmologistas \\
a tornarem-se mais perceptivos e se interessarem mais pelo tratamento \\
das complicações oculares da hanseníase. \\
\hline
\end{tabular}

Descritores: Hanseníase/epidemiologia; Hanseníase/complicações; Cegueira/prevenção \& controle; Infecções oculares bacterianas; Transtornos da visão

\section{EPIDEMIOLOGIA}

Nos últimos 25 anos, a hanseníase experimentou uma vertiginosa queda nos seus índices de prevalência em todo o mundo, principalmente nos países endêmicos, incluído o Brasil, que detêm ainda mais de $80 \%$ dos pacientes das Américas. Esse espetacular declínio ocorreu em decorrência da introdução da poliquimioterapia (PQT) instituída pela Organização Mundial da Saúde (OMS), capaz de tratar com êxito os pacientes paucibacilares (PB) e os multibacilares (MB) em regime de seis meses e um ano, respectivamente. Em 1975 havia 10 milhões de pessoas atingidas pela doença no mundo; em 1991, 5,5 milhões; chegando a menos de 1 milhão em $1995^{(1)}$. Atualmente esse número se aproxima de 213 mil pacientes ${ }^{(2)}$. No entanto, o índice de detecção da doença (254 mil) não decresceu proporcionalmente à prevalência, sugerindo que além do diagnóstico tardio, outros fatores não conhecidos possam estar interferindo nesses índices, já que a saída do registro ativo desses pacientes é tão somente por conta da brevidade e eficiência do tratamento, em tornar o paciente abacilífero ${ }^{(2)}$.

Hoje, 3 anos após a última data alvo para o controle da hanseníase, amplamente propalada pela OMS, há de se concordar que nenhuma das previsões quanto a esse objetivo se concretizou, e mesmo os pacientes "tecnicamente curados" continuam a necessitar de cuidados médicos especiais, seja pela possibilidade de recidiva, seja para tratamento de incapacidades ou surtos reacionais.

Somado a isso, pesquisas recentes no Brasil revelam um percentual de cegos em consequência da doença, de 4 a $11 \%$, que acrescidos da perda visual 
grave $(\mathrm{AV}<20 / 60$ a $20 / 200)$, pode elevar até $20 \%$ da população hanseniana com problemas sérios de visão ${ }^{(3-12)}$. Grande parte desses pacientes perderam a visão após a cura, seja por exposição prolongada de estruturas nobres do olho, como a córnea; seja por surtos reacionais repetitivos, sem a atenção que o caso requeria. Ultimamente várias publicações têm registrado também um número cada vez maior de lesões oculares consequentes a processos de hipersensibilidade, até mesmo no segmento posterior do olho, tais como: neurite óptica, edema cistóide da mácula e retinopatia serosa central ${ }^{(6)}$.

\section{A DOENÇA}

A doença é causada pelo M. leprae, um parasita intracelular obrigatório, de crescimento lento, não cultivado in vitro e que apresenta o espectro de formas clínicas que vão do polo tuberculóide (TT) ao Virchoviano (LL), que resultam da relação que se estabelece entre a resposta imune celular do hospedeiro e o parasita. As formas clínicas não são estáveis e episódios de agudização da doença são frequentes sugerindo quebra do equilíbrio imunológico. Dependendo do estado imunológico do paciente afetado, a doença pode variar de uma única mancha ou neurite, até a presença de nódulos, pápulas, úlceras, associados ou não com polineurite. A característica comum das manifestações cutâneas é a presença de hipoestesia.

\section{ALTERAC̄ÕES OCULARES}

As complicações oculares da hanseníase são responsáveis por alguns dos aspectos mais dramáticos da doença. A perda da visão somada ao déficit da sensibilidade tátil impõe uma carga adicional ao paciente, pois além de incapacitá-lo, o isola, roubando-lhe a independência, a capacidade de cuidar de si próprio e de se autossustentar.

A frequência e a gravidade dessas manifestações oculares dependem de vários fatores, como a forma clínica, o tempo de evolução da doença e principalmente a atenção do Sistema de Saúde, e variam na literatura de 30 a 100\% das populações estudadas $^{(4,6-8)}$

Há provavelmente entre 800 mil a 1 milhão de pacientes em todo o mundo com déficit visual grave ou mesmo que já perderam a visão por lesões sugestivas de hanseníase ${ }^{(2-6-9)}$, mas as estimativas são difíceis porque nem todos os estudos são consistentes ou facilmente comparáveis. Evidências mostram que a prevalência da cegueira em pacientes hansenianos, além dos fatores intrínsecos da doença, também é influenciada por outros; como o critério de definição de cegueira, natureza da amostragem, diferenças na metodologia de exames, variação do percentual de formas clínicas nas várias pesquisas, que são determinantes para as diferenças dos diversos índices de cegueira encontrados na literatura.

Segundo Choyce ${ }^{(9)}$, a cegueira entre os hansenianos é uma condição multicausal e pode ser determinada pelos seguintes processos, dentre outros. 1. Iridociclite insidiosa crônica de- vida a destruição do corpo ciliar pelo $M$. leprae que leva a uma falência progressiva da fisiologia ocular resultando em catarata complicada e phthisis bulbi; 2. Casos negligenciados de lagoftalmo pelo envolvimento do VII par que pode, ou não, estar associado à anestesia da córnea pelo envolvimento do ramo oftálmico do V par. Essa combinação causa exposição da córnea e ceratite neuroparalítica (Figura 5) com risco de perfuração do olho por infecções secundárias; 3 . Ceratite hansênica capaz de causar lesões substanciais da córnea com interferência na visão; 4 . Em grupo menor a cegueira pode ser devida à iridociclite plástica aguda com ou sem aumento secundário da pressão intraocular, geralmente na vigência de estados reacionais; 5 . Em um grupo menor ainda, a cegueira seria causada pela intercorrência de outras doenças como catarata e glaucoma de ângulo aberto.

\section{MECANISMOS DE COMPROMETIMENTO OCULAR}

Vários mecanismos são reconhecidos como responsáveis pelo envolvimento ocular na hanseníase:

\section{Exposição e anestesia}

O dano ao VII par craniano (facial) é comum na doença, afetando particularmente os ramos occipitotemporal e zigomático, produzindo paralisia seletiva no músculo orbicular. As fibras mais superficiais dos músculos são as mais comprometidas. Isso acontece em qualquer das formas clínicas da doença, porém é mais comum em associação com lesões tuberculóides da face, especialmente durante reações do tipo I e na forma Virchoviana (LL) não tratada, de longa duração. A invasão bacilar dos músculos superficiais da face pode contribuir para a perda do tônus observado na forma LL, resultando em lagoftalmo (Figuras 1 e 2) com limitação do fechamento das pálpebras com ressecamento da córnea e conjuntiva, torna-as mais susceptíveis aos traumatismos e infecção secundária (Figura 3). Na maioria dos pacientes, o mecanismo de defesa da córnea (fenômeno de Bell), no qual o globo ocular, comumente roda para cima durante o sono ou quando o paciente tenta fechar os olhos, compensa a incapacidade do fechamento das pálpebras (Figura 4). As reações nas lesões tuberculóides da face podem resultar em retração do tarso com instalação de entrópio e triquíase, que na presença de anestesia constituem agravos significativos para a córnea.

A anestesia da córnea e da conjuntiva é consequência da lesão do ramo oftálmico do $\mathrm{V}$ par craniano (trigêmeo) que ocorre quando uma lesão tuberculóide envolve o olho, ou quando há invasão bacilar dos nervos cranianos. A anestesia profunda leva à perda do pestanejamento reflexo propiciando ulceração da córnea que, se não for tratada prontamente, perfura levando a cegueira. O mecanismo produtor do afrouxamento da pálpebra inferior pode dever-se a pressão desigual sobre o tarso, em consequência da fibrose e encurtamento das fibras superficiais do orbicular, passando as fibras profundas a exercer maior força sobre o tarso evertendo a pálpebra, que aumenta a 


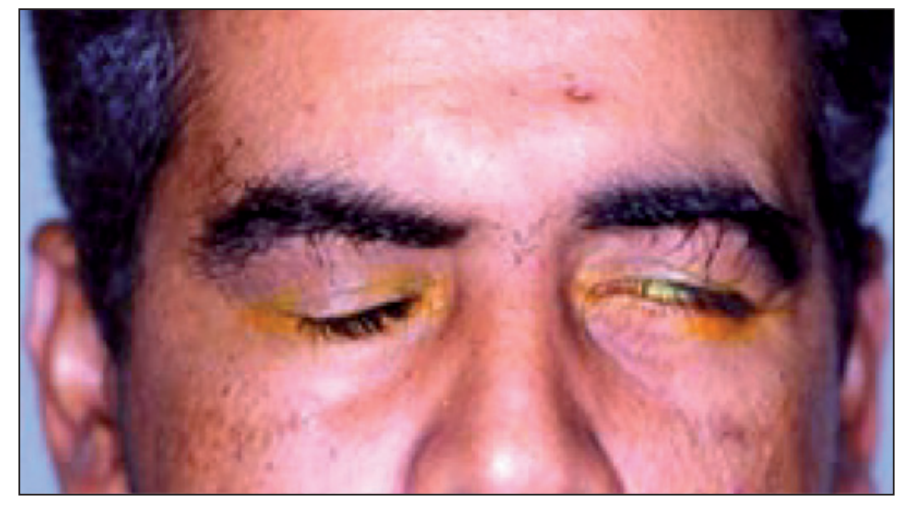

Figura 1 - Lagoftalmo moderado

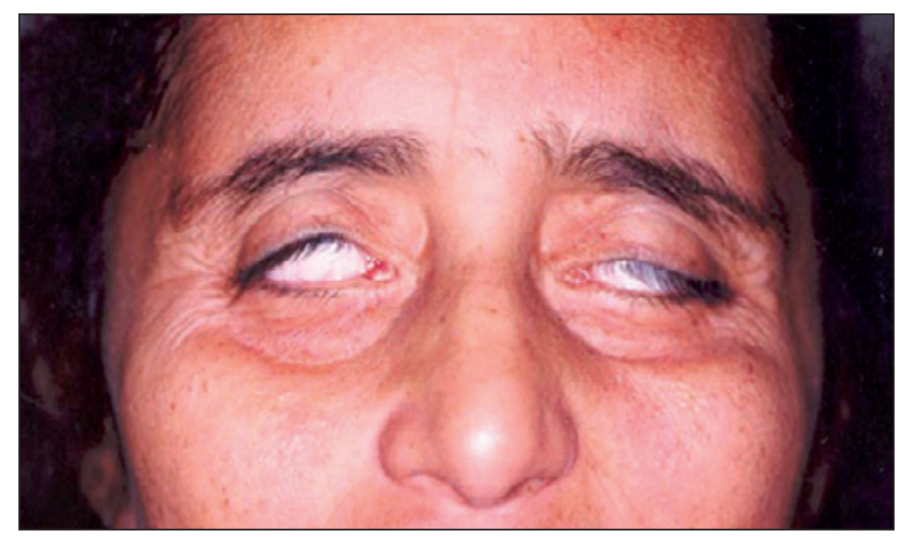

Figura 2 - Lagoftalmo grave

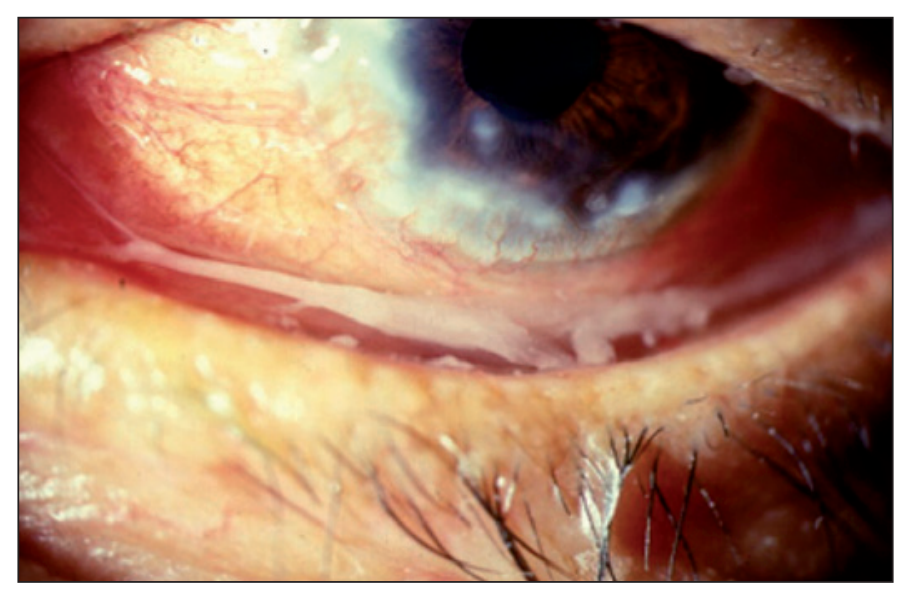

Figura 3 - Infecção secundária

exposição (Figura 5). Uma explicação alternativa é a atonia do orbicular provocada pela paralisia seletiva do facial. Os pontos lacrimais não tocam mais na conjuntiva e a lágrima flui pela borda palpebral - epífora (Figura 3).

A ulceração da córnea pode inicialmente ser superficial e só detectável com o exame biomicroscópico e, no caso de úlceras anestésicas, pelo lacrimejamento e reação da conjuntiva. As

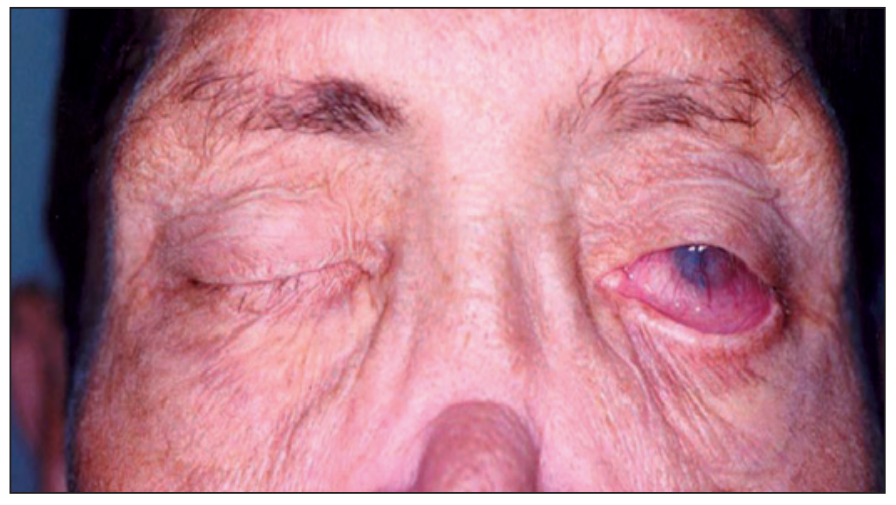

Figura 4 - Ausência do fenômeno de Bell

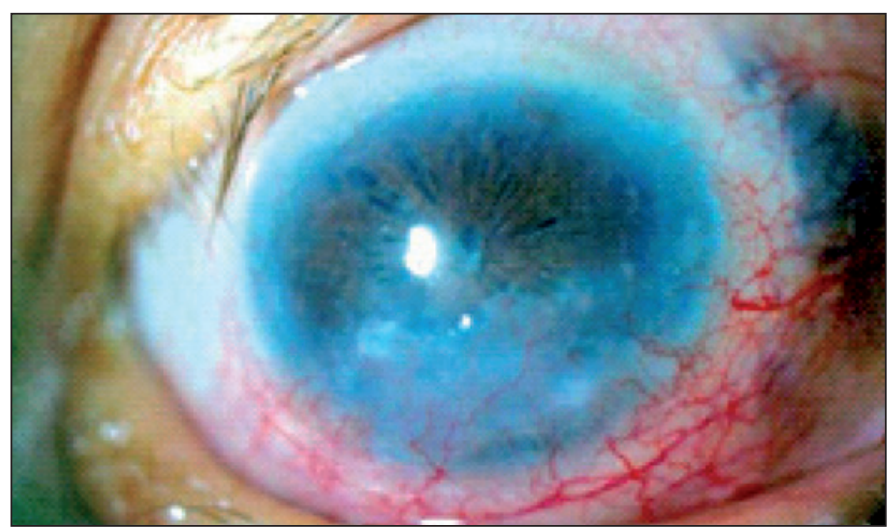

Figura 5 - Exposição da córnea

úlceras podem cicatrizar-se produzindo leucoma e desse modo interferindo com a visão. Restos inflamatórios colecionam-se na câmara anterior com formação de precipitados ceráticos, "flare" e células no aquoso, hipópio, com turvação da visão e formação posterior de sinéquias. Descontrolada a infecção invade e cega de forma inexorável (Figura 6). A infecção do saco lacrimal (dacriocistite) é fonte constante de perigo para o olho. Em virtude das lesões nasais da doença, especialmente as periostites e atrofia dos ossos nasais, a obstrução do ducto nasolacrimal pode levar à dacriocistite, considerando a alta intensidade da infecção nasal (Figura 6).

\section{Invasão bacilar}

Nas formas multibacilares o olho é invadido pelo bacilo, através da corrente sanguínea, resultando quase sempre no comprometimento bilateral com formação de nódulos conjuntivais e, subsequentemente, comprometimento da córnea e úvea anterior. Os bacilos se multiplicam no corpo ciliar, tornando essa estrutura juntamente com a íris, bastante vulneráveis às reações inflamatórias - iridociclites (Figura 7). Essas complicações são consideradas como a causa mais grave de cegueira entre os hansenianos.

As primeiras manifestações clínicas da invasão bacilar da córnea são as ceratites puntatas (Figura 8): pequenas opacida- 


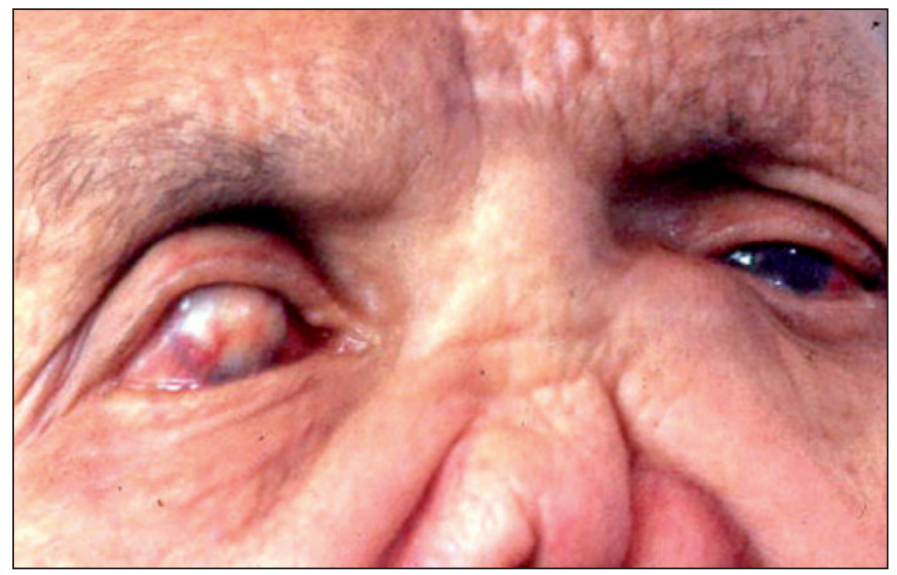

Figura 6 - Dacriocistite

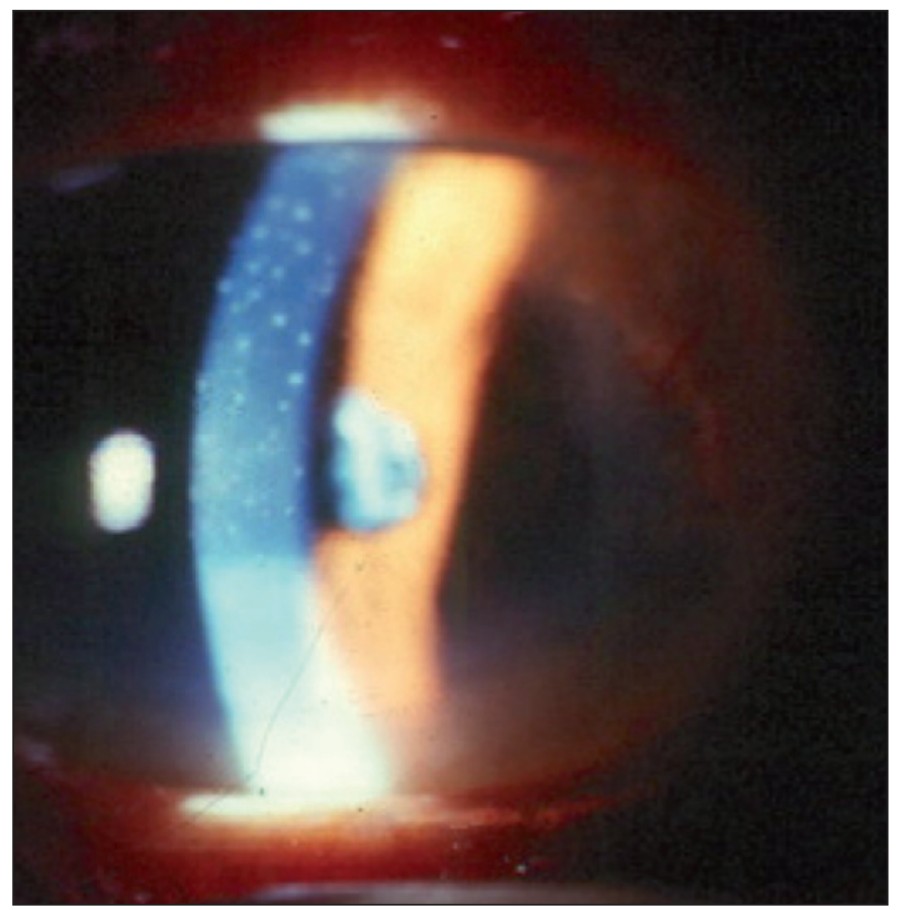

Figura 7 - Iridociclite

des esbranquiçadas que podem coalescer comprometendo a transparência da membrana de Bowmann com formação posterior de pannus.

$\mathrm{Na}$ íris, a formação de nódulos (Figura 9) pode constituir o único sinal visível da invasão do bacilo no trato uveal indicando o envolvimento de todo o segmento anterior, permanecendo o quadro assintomático até que se instalem estados reacionais.

\section{Hipersensibilidade}

Os tecidos oculares podem ser sítios de reações imunológicas durante a evolução da hanseníase e podem ser lesados na presença ou na ausência de bacilos, especialmente o corpo ciliar e a íris, o que resulta na manifestação que, segundo a

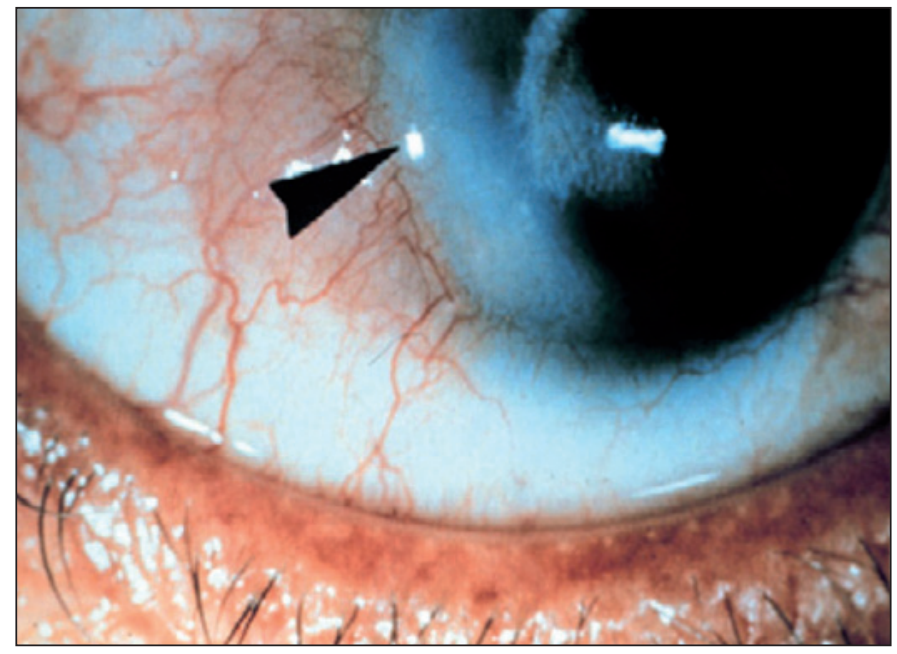

Figura 8 - Ceratite puntata (Cortesia do Prof. Fernando Oréfice)

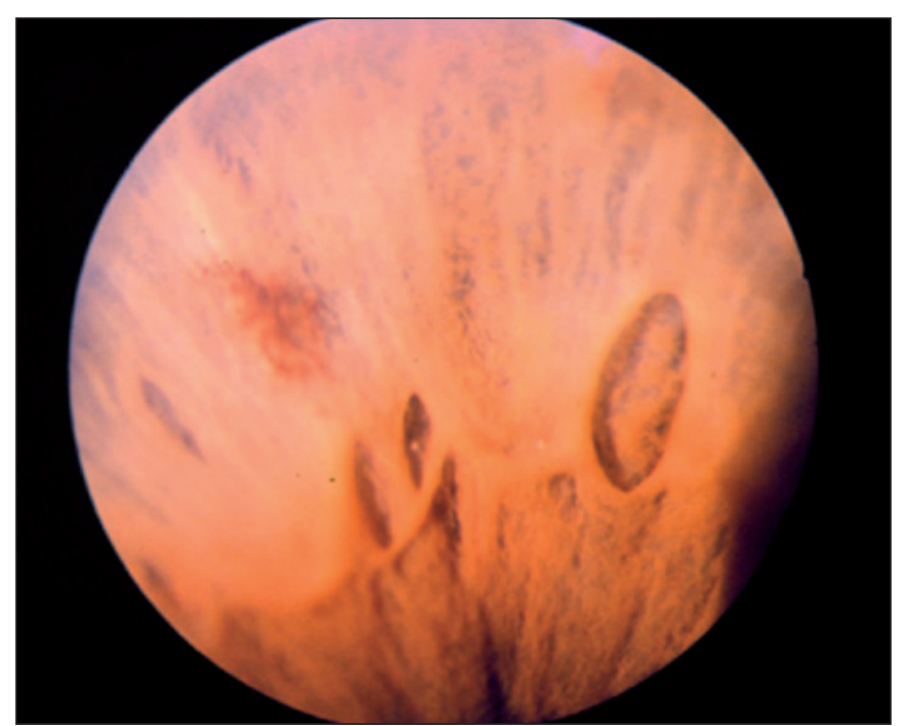

Figura 9 - Nódulo de Íris (Cortesia do Prof. Fernando Oréfice)

maioria dos autores é a mais grave que leva à cegueira - iridociclite aguda (Figura 12). O quadro inclui dor, fotofobia com lacrimejamento, turvação da visão, injeção perilímbica, seclusão pupilar e turvação do aquoso com exsudato inflamatório (células e proteínas) e pode evoluir para formas subagudas ou crônicas.

Às vezes a túnica externa constitui sitio de reação ocorrendo hiperemia e dor, visível através da conjuntiva - episclerite. A inflamação crônica do tecido escleral adelgaçado permite a herniação do tecido uveal - estafiloma (Figura 11).

No processo da iridociclite podem ocorrer sinéquias anteriores e posteriores, que podem obstruir o fluxo do aquoso através da pupila levando a um glaucoma secundário. As goniossinéquias dificultam a saída do aquoso através do canal de Schlemm, podendo ambos esses processos levar a um glaucoma. Trata-se de uma complicação frequente da iridiociclite (Figura 7) recorrente. Por outro lado, uma neuropatia 


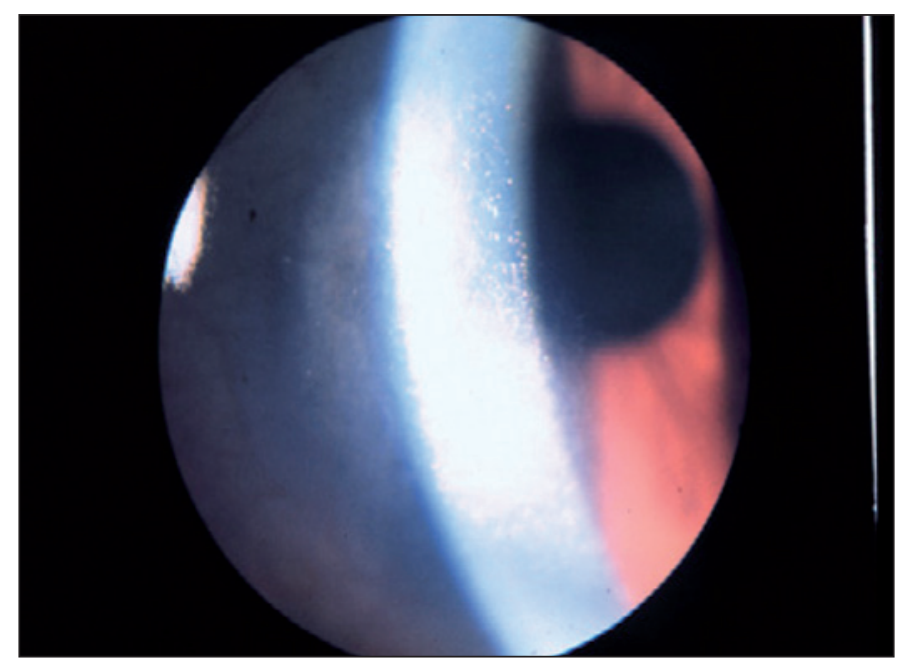

Figura 10 - Ceratite puntata (Cortesia do Prof. Fernando Oréfice)

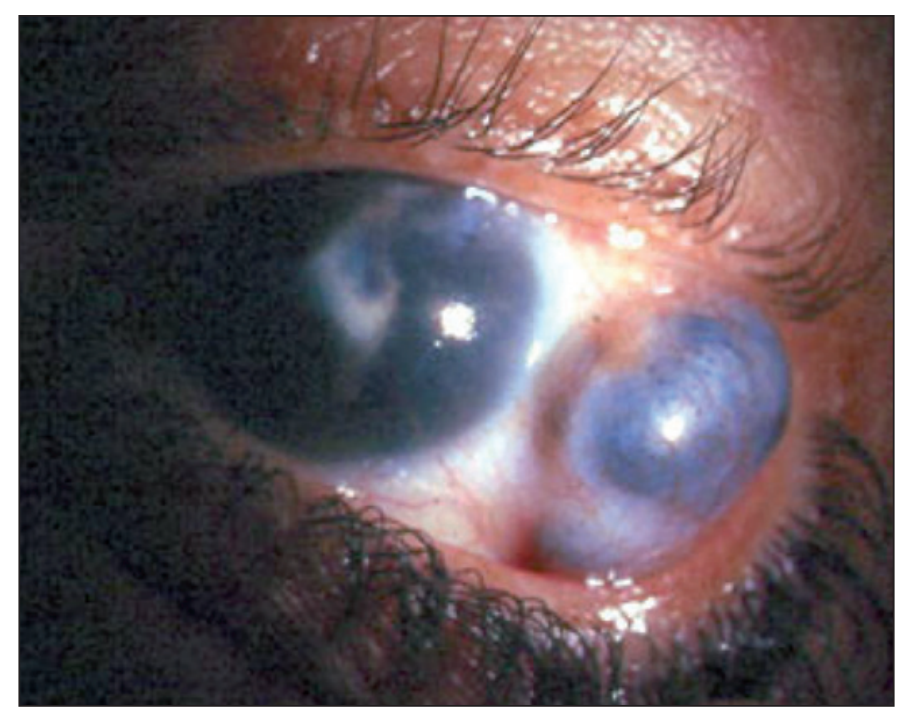

Figura 11 - Estafiloma

precoce do sistema nervoso autônomo pode comprometer o controle adrenérgico local do eixo corpo ciliar, malha trabecular, justificando a incidência aumentada de hipotensão ocular entre os hansenianos.

\section{COMENTÁRIOS}

É verdade que o Ministério da Saúde do Brasil tem desenvolvido um trabalho profícuo no combate a hanseníase endêmica por aqui, principalmente com a polioquimioterapia, mas é necessário que além desse esforço, seja dada a atenção multidisciplinar ao paciente hanseniano. Excetuando esforços isolados de pessoas abnegadas em poucos serviços no Brasil, não há na rede pública de atenção à saúde centros especializados em Oftalmologia para a atenção multidisciplinar ao paciente hanseniano.

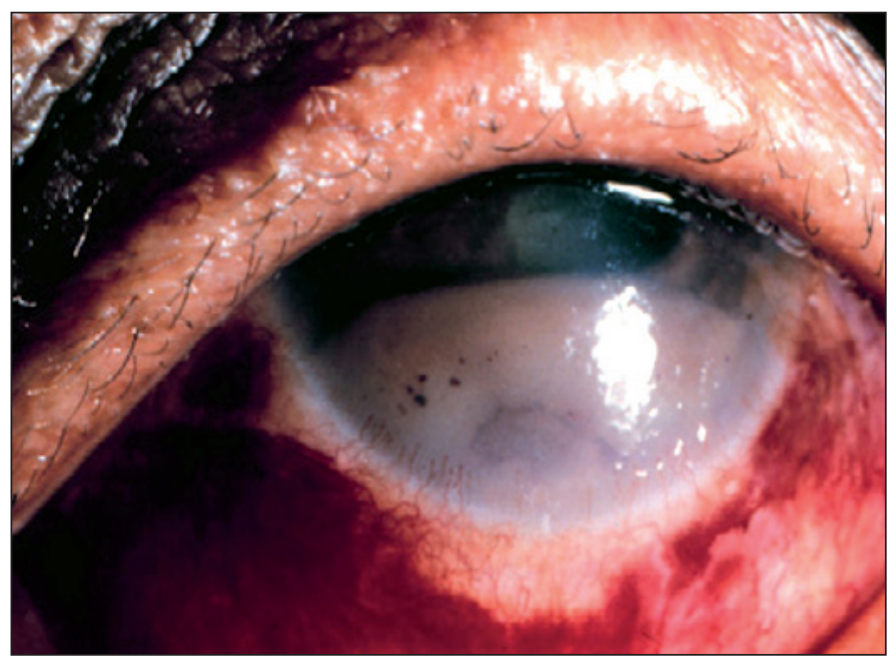

Figura 12 - Iridociclite aguda (Cortesia do Prof. Fernando Oréfice)

Como observamos, as alterações oculares e todas as outras manifestações podem ocorrer na vigência ou após o tratamento quando o paciente é considerado tecnicamente curado e sai do registro ativo. Aí ocorre a primeira falha: o paciente perde a sua referência e não encontra na rede pública ou privada, pessoal capacitado para o seu atendimento e quando encontra, se defronta com o estigma ${ }^{(10)}$. É preciso que se humanize este serviço, pois o hanseniano é um cidadão merecedor de ações de saúde implementadas seriamente. É preciso que as autoridades de saúde no Brasil tenham determinação de enfrentar a hanseníase, não só como uma doença infecciosa crônica, mas também como uma doença imunológica, espectral, cujo paciente carece de atendimento multidisciplinar por toda a vida, principalmente os que se situam no espectro grave (MB) da doença ${ }^{(10)}$.

A euforia da eliminação passou. Tratemos agora os pacientes hansenianos com a atenção de que necessitam e merecem como cidadãos.

É oportuno propor ao Ministério da Saúde a separação da classificação de graus de incapacidades das mãos, pés e olhos, atualmente classificados conjuntamente. Não são relacionáveis ${ }^{(5)}$. O sentido da visão há de ter uma avaliação melhor, mais elaborada e que detecte mais precocemente as lesões decorrentes da doença. Para isso é necessário pessoal treinado e equipamentos oftalmológicos já disponíveis atualmente no mercado. Só assim se deixará de fazer diagnóstico de lesões oculares tardiamente ou mesmo fazer exame oftalmológico com lupa, filtro de café e fio dental ${ }^{(11-13)}$.

Com vontade política das autoridades sanitárias a qualidade dos cuidados dos olhos dos pacientes hansenianos pode melhorar muito, prevenindo-se a cegueira de forma efetiva, pois lamentavelmente esses pacientes, antes de perderem a visão, já perderam o sentido substituto - o tato.

No Brasil, o cuidado com os olhos dos pacientes hansenianos experimentou dois estágios: na década de 40 com os trabalhos do Dr. Mendonça de Barros ${ }^{(14)}$, um pesquisador de ponta, 
publicou muito na literatura mundial e ajudou a elucidar algumas alterações oculares importantes. Dessa época até a década de 80 muito pouco ou nada se fez pela saúde ocular dos hansenianos no Brasil. Por justiça, após a década de 1980 o Prof. Fernando Oréfice ${ }^{(15)}$, pesquisador sério e humanitário liderou um grupo de oftalmologistas entre os quais me incluo e usando a tecnologia disponível atualmente, conseguiu resgatar a verdade científica sobre a principal causa de cegueira entre os hansenianos, até então tida como sendo a uveíte pela literatura mundial. Os trabalhos brasileiros demonstram que a lesão na córnea é a principal causa de cegueira, e a que mais facilmente pode ser prevenida.

Que mais oftalmologistas se interessem pelas alterações oculares em hansen, e deixemos de hipocrisia, pois por muito tempo, teremos de tratar esse mal e suas complicações.

\section{ABSTRACT}

A sharp drop in the prevalence of leprosy occurred in the last three decades. However, the incidence has not decreased at the same rate. Three years after the World Health Organization last deadline for leprosy control, patients considered healed still need special care for their incapacities and immunopathological reactions. Medical literature reffers blindness in $4 \%$ to $11 \%$ of studied patients and more than $20 \%$ with severe visual problems due to corneal exposure, bacillary invasion and hipersensibility. These mechanisms result in a population of nearly one million blind leprosy patients even though official prevalence accounts no more than 250,000 patients worldwide. The author calls for better patients management and follow-up and urges ophthalmologists to become more aware and interested in the treatment of the ocular complications of leprosy.

Keywords: Leprosy/epidemiology; Leprosy/complications;
Blindness/prevention \& control; Eye infections; Bacterial; Vision disorders

\section{REFERÊNCIAS}

1. World Health Organization. Action Programme for the Elimination of Leprosy [Internet]. Geneva: WHO. [cited 2004 Jan 19]. Available from: http://www. who.int/lep

2. World Health Organization.Action Programme for the Elimination of Leprosy [Internet]. Geneva: WHO; 2007. [cited 2007 Dec 13]. Available from: http:// www.who.int/lep

3. Schelini SA. Prevalência de alteração óculopalpebral na população hanseniana. Arq Bras Oftalmol. 1992;55(4):178-92. [Apresentado no 10ํㅜㄹ Congresso Brasileiro de Prevençäo da Cegueira, 1992 Set 3-6; Manaus].

4. Oliveira Neto HL, Silva JL, Manso PG, Botene IM, Sartori MB.Envolvimento ocular na hanseníase: estudo em pacientes de ambulatório. Arq Bras Oftalmol. 1996;59(2):162-70.

5. Medina NH, Brasil MT, Marzliak ML, Lafratta TE, Vieth H. Implementação da vigilância das incapacidades oculares em hanseníases [poster]. Arq Bras Oftalmol. 1999;62(4):426. [Apresentado no 30 Congresso Brasileiro de Oftalmologia; 1999 Set 4-7; Recife].

6. Cohen JM. Estudo epidemiológico das alterações oculares em hansenianos no Amazonas [tese]. Ribeirão Preto: Universidade de São Paulo; 1996.

7. Passerotti S. Prevenção e tratamento dos comprometimentos oculares na hanseníase [resumo]. Arq Bras Oftalmol. 1992;55(4):178-92. [Apresentado no $10^{\circ}$ Congresso Brasileiro de Prevençäo da Cegueira, 1992 Set 3-6; Manaus.

8. Costa MS, Gallo ME, Nery JÁ, Bechimol E. Avaliação oftalmológica em hanseníase multibacilar. Arq Bras Oftalmol. 1999;62(6):701-3.

9. Choyce DP. Blindess leprosy. Trop Doct. 1973;3(1):16-9.

10. Opromola DVA. Hanseníase após a cura. Hansenol Int. 1998;23(1):1-2.

11. Barros JM. The ocular complications of leprosy. Am J Ophthalmol. 1946;29: $162-9$.

12. Monteiro LG, Campos WR, Oréfice F, Grossi MAF. Estudo das alterações oculares em hansenianos de controle ambulatorial. Rev Bras Oftalmol. 1992;51 (3): $167-70$.

13. Vieth H, Salotti SR, Passerotti S. Guia de prevenção ocular em hanseníase. Bauru: Instituto Lauro de Souza Lima; s.d. p.7.

14. Courtright P, Johnson GJ. Prevenção da cegueira em hanseníase. São Paulo: Secretaria da Saúde, Serviço de Oftalmolgia Sanitária; 1994.

15. Courtright P, Lewallen S; Teaching and Learning Materials Ilep. Guide to ocular leprosy for health workers:a training manual for eye care in leprosy. Singapore:Word Scientific; 1993. p.43. 